\title{
Conservative treatment of a comminuted cervical fracture in a racehorse
}

Vos, N.J.

Unit of Veterinary Surgery, University Veterinary Hospital, School of Agriculture, Food Science and Veterinary Medicine, University College Dublin, Belfield, Dublin 4, Ireland

Current contact details: University Veterinary Centre Camden, Faculty of Veterinary Science, The University of Sydney, 410 Werombi Road, Camden, New South Wales 2570, Australia

Tel: 0061246550777

Fax: 0061246551212

Email: nvos@mail.usyd.edu.au

The 'classical' or 'Hangman' neck fracture involves the odontoid peg (process) of the second cervical vertebra (C2), and is described as an axial, dens or odontoid peg fracture in both the veterinary and human literature. Possible surgical treatment in both foals and adult horses requires a technique that allows decompression, anatomical alignment and stabilisation of the odontoid fracture. A limited number of surgical cases in foals have been reported in literature, but never in an adult horse. A mature Irish Thoroughbred racehorse was diagnosed with a type 2 a odontoid peg fracture. Clinical signs included reluctance to move the head and neck, a left hind limb lameness and a neurological status of grade 2 . The horse was treated conservatively and raced successfully five months after the diagnosed injury.

Key Words: cervical, equine, fracture, odontoid, vertebra

Volume 61 Number 4 244-247, 2008

\section{Introduction}

There are seven cervical vertebrae in the horse: C1-C7. Cervical vertebral fractures are not uncommon in horses but usually involve the more caudal cervical vertebrae (Nixon and Stashak, 1988; Nixon, 1996). Vaughan and Mason (1976) reported 10 fractures of the axis over a three-year period in the United Kingdom. None of these were odontoid peg fractures; instead they involved the caudal body of C2. Krook and Maylin (1988) reported three fractures of the cervical vertebrae in a total of 192 breakdown injuries in the United States, none of which involved the dens. This case report describes a fracture of the odontoid process of the axis $(\mathrm{C} 2)$.

The odontoid peg originates embryonically from the body of $\mathrm{C} 1$. The axis (C2) has separate centres of ossification for the dens (odontoid peg), head, body and caudal epiphysis. The physis of the odontoid peg closes by the age of seven to nine months (Butler et al., 2000). Cranial cervical fractures, such as fractures of the axial dens, are therefore more commonly seen in young horses (less than six months old) (Owen and Smith Maxie, 1978; Slone et al., 1979; Wagner et al., 1979; McCoy et al., 1984; Nixon, 1996).

Young, excitable animals may injure the immature cervical vertebrae by rearing and falling during play or training. Hyperextension and/or hyperflexion of the neck have been reported, resulting in (sub) luxation lesions of the occipitoatlantoaxial region, with or without various combinations of vertebral body and articular process fractures (Funk and Erickson, 1968; Guffy et al., 1969; Slone et al., 1979; Robinson and Currall, 1981; Nixon and Stashak, 1988; Nixon, 1996). Adult horses are more commonly injured in high-speed paddock or race accidents (Nixon, 1996). Clinically, foals can show variable neurological signs ranging from paraplegia and tetra-paraplegia to less severe ambulatory neurological deficits. Significant narrowing of the spinal canal due to atlanto-axial instability leads to the development of an inflammatory pannus which can progress and result in spinal cord compression and neurological deficits (Owen and Smith Maxie, 1978; Slone et al., 1979; McCoy et al., 1984; Nixon and Stashak, 1988; Nixon, 1996). Adults are more likely to be non-ambulatory after fractures of the cervical spinal vertebrae, although the majority of these fractures include the more caudal cervical vertebrae (Nixon and Stashak, 1988; Nixon, 1996). Odontoid peg fractures and their associated treatments have been reported in adult humans, dogs and cows (Julian and Maxwell, 1963; Gage, 1968; Trotter, 1972; Anderson and D'Alonzo, 1974). Odontoid peg fractures are the most common fractures of $\mathrm{C} 2$ in humans. Ten per cent of unconscious people brought to a hospital emergency room following a motor vehicle accident in the United States had C2 fractures, of which $80 \%$ were odontoid process fractures (Belaval and Roy, 2005).

To substantiate clinical observations, methodically defined radiographical evaluation has to be applied (Ryan, 1982).

The radiographical system most widely used, with regards to odontoid process fractures in humans, is that of Anderson and D'Alonzo, which dates from 1974, and describes four types of odontoid fractures (Ryan, 1982; Graziano et al., 1993). The difference in fracture configuration is based on the anatomical location of the fracture line(s) and the presence of bone fragmentation 
Table 1: Classification of odontoid process fractures of the second cervical vertebrae in the horse (Anderson et al. 1974). The table is a proposed equine adaptation of a human classification scheme

\begin{tabular}{|l|l}
\hline Type I & $\begin{array}{l}\text { An oblique fracture line through the upper part of the } \\
\text { odontoid process representing an avulsion fracture }\end{array}$ \\
\hline Type II & $\begin{array}{l}\text { A fracture at the junction between the odontoid } \\
\text { process and the body of the axis }\end{array}$ \\
\hline Type IIA & $\begin{array}{l}\text { Similar to type II but with fragments of bone present } \\
\text { at the fracture site }\end{array}$ \\
\hline Type III & $\begin{array}{l}\text { A fracture that extends down into the cancellous } \\
\text { bone of the body of the axis and, in reality, is a } \\
\text { fracture of the body of C2 }\end{array}$
\end{tabular}

(Table 1). The optimal treatment of fractures of the odontoid process in humans is the subject of debate and seems to be dependent on the type of the odontoid fracture (Anderson and D'Alonzo, 1974; Ryan, 1982; Graziano et al, 1993; Verheggen and Jansen, 2004).

Retrospective studies into fatalities during racing in several countries mention certain types of neck fractures in the horse (Lundvall, 1969; Vaughan and Mason, 1976; Gelberg, 1985; Krook and Maylin, 1988; Johnson, 1994; Estberg, 1996; Bailey, 1997; Bailey et al., 1998; Boden et al., 2007a, 2007b). However, the incidence and configuration of odontoid process fractures in the horse is, to the author's knowledge, unknown.

A suitable surgical technique for horses would allow decompression, anatomical alignment and stabilisation of the odontoid peg fracture. Several surgical repairs in foals have been reported in the literature (Owen and Smith Maxie, 1978; McCoy et al., 1984); however, little has been written on the subject in mature horses. This report reviews the clinical features, diagnostic procedures and outcome of a mature horse presented with a fracture of the odontoid process. The author adopted the classification system described by Anderson and D'Alonzo in 1974. The purpose of this communication is to report the successful outcome following conservative management of an odontoid peg fracture in an adult Thoroughbred.

\section{Case history}

A nine-year-old Irish Thoroughbred racehorse gelding was referred to the University Veterinary Hospital at University College Dublin. The horse had competed successfully in flat and hurdle races in the past. A fall backwards from the loading ramp had occurred two weeks prior to referral to the clinic. Immediately after the incident, the horse was not clinically or neurologically compromised. However, when the horse was put out to pasture the week after the incident, neck stiffness and discomfort were noticed. In the days

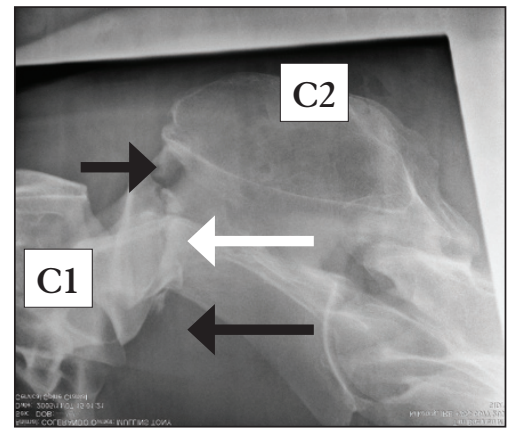

Figure 1: Lateral view of the cranial cervical vertebrae (C1-C2) of a nine-year-old Thoroughbred racehorse, two weeks after trauma. An odontoid process type $2 \mathrm{a}$ fracture (white arrow), with dorsal and ventral fragmentation (black arrows), is visible around the vertebral canal. It is possible that these fragments were lateralised which limited their impingement on the spinal cord. immediately prior to referral, the horse had been slightly depressed, the head was held at shoulder level and lateral movement of the neck to the side provoked an adverse reaction.

On clinical examination, the horse appeared bright, alert and responsive. The occipital protuberance of the head was kept level with the dorsal spinal processes of the first vertebrae of the thorax. A subtle swelling on the left and right sides of the neck at the level of the first two to three cervical vertebrae was visible. Deep digital palpation of the cranial cervical region elicited pain. Passive flexion and extension of the neck, ventrally, dorsally and laterally, were difficult to perform, and the horse became increasingly less cooperative. Ventral movement of the head and neck was especially impaired/reduced. The horse was able to walk normally and no obvious lameness was visible. However, a left hind limb (LH) lameness, two out of five at a trot, was noted. LH lameness in this horse had not been previously noted by the owner. A distinct decreased foot-arch was present and the LH foot was toe catching almost continuously. No obvious physical abnormalities on the LH limb were noted; flexion tests were performed but the lameness did not change. Crossing the LH limb with the right hind (RH) limb resulted in a correction. Crossing the RH with the LH limb did not result in a satisfactory correction and the horse lost its balance, almost falling over. A sway test was performed while the horse was standing and walking and the pelvic limb strength and proprioceptive functions seemed unaffected. Furthermore, no circumduction of either of the rear limbs was noted while turning. Perineal reflexes were checked and resulted in contraction of the anus and clamping of the tail in response to stimulation of the skin in this region. The neurological status of the horse was marked as a grade 2 (deficits noted at the walk) (DeLahunta, 1983). The lameness was not further investigated at this stage. Radiography of the head and neck was performed. The lateral radiograph of the cranial cervical vertebrae revealed a fracture of the odontoid process of the second cervical vertebra (Figure 1). Subluxation of the atlantoaxial joint and a comminuted type 2 a fracture of the odontoid peg were clearly visible. Several osseous fragments were visible, dorsal and ventral to the base of the odontoid process. The space between the dorsal aspect of the odontoid peg and the ventral aspect of the dorsal lamina of the atlas was significantly narrowed and the odontoid peg was dislocated ventrally. Since no reports of successful surgical repair of such fractures were found or were known to the author, a conservative approach was discussed with the owner. An attempt was made to splint the neck in an effort to align and stabilise the $\mathrm{C} 2$ fracture. The patient was discharged the same day, with instructions to stable rest for at least four months. The horse was fed from shoulder level and treated with $1 \mathrm{~g}$ of phenylbutazone PO BID for two weeks (Equipalazone; Arnolds, United Kingdom). The neck splint resulted in discomfort and was therefore removed by the owner after several days.

Several months later, the owner informed the author 


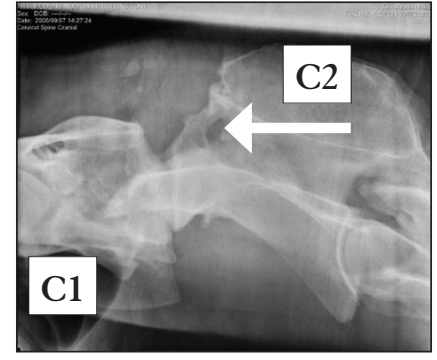

Figure 2: Lateral view of the cranial cervical vertebrae (C1-C2) of a nineyear-old Thoroughbred racehorse eight months after the fracture was first diagnosed. The odontoid fracture is completely fused (white arrow).

that the horse had improved dramatically. The neck pain and abnormal head and neck posture had disappeared completely within the weeks following the visit to UCD. Radiographs taken eight months after the initial diagnosis showed the satisfactorily reduction and alignment of the odontoid process fracture (Figure 2).

The horse was now left in a small paddock, and the left hind limb lameness appeared to resolve. Four months after the diagnosed C2 fracture, the horse returned to training and finished his first flat race in second place. However, a left fore limb lameness unfortunately curtailed his career after this, and a tendon injury was diagnosed.

\section{Discussion}

This present case illustrates that an odontoid fracture, although ostensibly catastrophic from a radiographic point of view, can be well tolerated for weeks, with relatively minor signs. As the occurrence and the surgical management of this type of fracture have not been reported in the adult horse and the neurological deficits were relatively mild, conservative management was adopted in this case. Taking into consideration the large anatomical (Anderson and D'Alonzo, 1974; DeLahunta, 1983; Nixon, 1996) and biomechanical similarities (Anderson and D’Alonzo, 1974; Clayton and Townsend, 1989; Nixon, 1996) leading to odontoid peg fractures in man and horses, an adaptation of the Anderson and D'Alonzo's classification scheme seemed reasonable in the author's view. This particular classification could be useful with regards to future discussion concerning odontoid fracture incidence and possible treatment options.

An important prognostic factor for successful surgical or conservative treatment outcome in man and foals is the severity of the neurological deficits. Although the severity of the inflicted trauma to the spinal cord is not easily established (Papageorges et al., 1987), several mechanisms are likely to be the cause of different degrees of neurological signs. The first mechanism involves direct trauma to the spinal cord through pressure of fractured vertebral fragments and/or severe displacement of the odontoid process, as mentioned by Owen and Smith Maxie (1978). The second mechanism involves narrowing of the spinal canal due to the atlanto-axial joint instability leading to development of an inflammatory pannus, resulting in delayed spinal cord compression and neurological deficits (Owen and Smith Maxie, 1978; Slone et al., 1979; McCoy et al., 1984; Papageorges et al., 1987; Nixon and Stashak, 1988; Nixon, 1996).

Steele's rule of thirds states that the dens, subarachnoid space and spinal cord each occupy one third of the area of the canal at the level of the atlas with a substantial reduction in subarachnoid space caudal to the atlas (Anderson and D'Alonzo, 1974). That relatively large subarachnoid space at the atlantoaxial level allows more distention of the spinal cord after trauma, hence the possible lack of major neurological signs in this particular case. Formation of an epidural haematoma may constitute a third mechanism by compressing the cord acutely over a wide region. Many of these horses have progressively deteriorating neurological signs and require decompression to prevent the extensive vascular compromise to the spinal cord that may result in progressive myelomalacia (Sandier and Tatot, 1976; Braund, 1981). A study performed by Papageorges et al. (1987) showed that compressive lesions were rarely found at C1$\mathrm{C} 2$ level in horses. Few horses with these fractures show neurological deficits in the acute stage, largely because of the spacious vertebral canal at the level of the atlas. Late onset of clinical ataxia following injury to the atlantoaxial region has been attributed to callus formation within the vertebral canal at the level of the atlas (Nixon, 1996).

The lateral radiographs taken of this horse were vital from a diagnostic point of view. To ascertain the stability of the fracture, flexed and extended lateral views could have been taken. Unfortunately, survey radiographs are not reliable for the diagnosis of compressive lesions of the cervical spinal cord in horses. Standardised myelographic examination can be used to demonstrate compressive spinal cord lesions more accurately than survey radiography (Papageorges et al., 1987; Nixon, 1996). However, several authors have sugested that there may be complications associated with the induction of and recovery from general anesthesia, including possible exacerbation of the fracture. (Papageorges et al., 1987; Barnes et al., 1995).

Surgical repair of odontoid process fractures can be challenging. Several techniques have been described in foals such as: compression plating (McCoy et al., 1984); Steinmann pin fixation (Owen et al., 1978); lag screw fixation (Wagner et al., 1979; Barnes et al., 1995); dorsal laminectomy (Slone et al., 1979; Nixon et al., 1988); and, ventral cervical fusion (Grant et al., 1985). To the author's knowledge, no surgical reports of odontoid fracture repair in mature horses have been published. In this case, an attempt was made to immobilise the neck with a bandage incorporating wooden splints. The horse showed signs of severe discomfort and stress and, as a result, the bandage was removed. Successful use of fibreglass neck casts, Robert Jones neck bandages and a surcingle placed around a foal's chest and strapped to the halter have been described (Owen and Smith Maxie, 1978; Schneider, 1981).

Physical examination is an essential step in evaluating potential treatment options. The method of treatment varies depending on the severity of the neurological signs, the intended use of the horse and financial constraints. Surgical treatment may be indicated when progressive deterioration is apparent. However, horses that are already recumbent at the time of surgery are poor candidates for surgical fracture realignment and plate fixation (Nixon, 1996). If the 
neurological signs are not too severe and pain perception is present, conservative treatment can be indicated, as is common practice in human surgery. The author is aware that future neurological signs may develop, but an initial conservative approach towards adult horses with odontoid peg fractures, seems to be a very viable option. In this case, a mature Irish Thoroughbred racehorse was diagnosed with a type 2 a odontoid peg fracture. Clinical signs included reluctance to move the neck and head, dullness, a left hind limb lameness and a neurological status of grade 2 (DeLahunta, 1983). Conservative treatment was chosen and the horse raced successfully following the injury.

\section{Conclusion}

This case illustrates that an odontoid fracture, although ostensibly catastrophic from a radiographic point of view, could be well tolerated for months, with relatively minor clinical signs. As the occurrence and the surgical management of this type of fracture have not been reported in the adult horse and the neurological deficits were relatively mild, conservative management was successfully adopted in this case.

\section{Acknowledgments}

The author would like to express his gratitude towards the veterinary team of UVH, University College Dublin and to Dr T Brennan, who referred the horse to the hospital and provided the follow-up radiographs.

\section{References}

Anderson, L.D and D'Alonzo, R.T. (1974). Fractures of the odontoid process of the axis. Journal of Bone and Joint Surgery (American) 56A: 1663-1674. Bailey, C. (1997). Wastage in the Australian Thoroughbred racing industry: a survey of Sydney trainers. Australian Veterinary Journal 75: 64-66. Bailey, C., Reid, S., Hodgson, D., Bourke, J. and Rose, R. (1998). Flat, hurdle and steeple racing: risk factors for musculoskeletal injury. Equine Veterinary Journal 30: 498-503.

Barnes, H.G., Tucker, R.L., Grant, B.D., Roberts, G.D. and Prades, M. (1995). Lag screw stabilization of a cervical vertebral fracture by use of computed tomography in a horse. Journal of the American Veterinary Medical Association 206: 221-223.

Belaval, E. and Roy, S. (2005). Fractures to the Cervical spine. Journal of American College of Emergency Physicians 19 (11): 2-11.

Boden, L.A., Anderson, G.A., Charles, J.A., Morgan, K.L., Morton, J.M., Parkin, T.D.H., Clarke, A.F. and Slocombe, R.F. (2007a). Risk factors for Thoroughbred racehorse fatality in jump starts in Victoria, Australia (19892004) Equine Veterinary Journal 39: 22-428

Boden, L.A., Anderson, G.A., Charles, J.A., Morgan, K.L., Morton, J.M., Parkin, T.D.H., Clarke, A.F. and Slocombe, R.F. (2007b). Risk factors for Thoroughbred racehorse fatality in flat starts in Victoria, Australia (1989-2004) Equine Veterinary Journal 39: 430-437.

Braund, K.G. (1981). Acute spinal cord traumatic compression. In: Pathophysiology in Small Animal Surgery. MJ Bojrab (ed.) . Philadelphia: Lea \& Febiger.

Butler, J.A., Colles, C.M., Dyson, S.J., Kold, S.E. and Poulos, P.W. (2000). The spine. In: Clinical Radiology of the Horse. Second edition. United Kingdom: Blackwell Science.

Clayton, H. M. and Townsend, H. G G. (1989). Kinematics of the cervical spine of the adult horse. Equine Veterinary Journal 21: 189-192.

DeLahunta, A. (1983). Veterinary Neuroanatomy and Clinical Neurology.
Second edition. Philadelphia, WB Saunders.

Estberg, L. (1996). Fatal musculoskeletal injuries incurred during racing and training in Thoroughbreds. Journal of the American Veterinary Medical Association 208: 92-96.

Funk, K.A. and Erickson, E.D. (1968). A case of atlanto-axial subluxation in a horse. Canadian Veterinary Journal 9: 120-123.

Gage, E.D. (1968). Surgical repair of a fractured cervical spine in the dog. Journal of the American Veterinary Medical Association 153: 1407-1411. Gelberg, H. (1985). Sudden death in training and racing Thoroughbred horses. Journal of the American Veterinary Medical Association 187: 1354-1356. Grant, B.D., Hoskinson, J.J. and Barbee, D.D. (1985). Ventral stabilization for decompression of caudal cervical spinal cord compression in the horse. Proceedings American Association of Equine Practitioners 32: 75-90.

Graziano, G., Jaggers, C., Lee, M. and Lynch, W. (1993) A comparative study of fixation techniques for type II fractures of the odontoid process. Spine 16: 2383-2387.

Guffy, M.M., Cofpman, J.R. and Strafuss, A.C. (1969). Atlantoaxial luxation in a foal. Journal of the American Veterinary Medical Association 155: 754-757.

Johnson, B. (1994). Causes of death in racehorses over a two-year period. Equine Veterinary Journal 26: 327-330.

Julian, R.J. and Maxwell, T.W. (1963). Fracture of the cervical vertebrae in a heifer. Canadian Veterinary Journal 4: 29-30.

Krook, L. and Maylin, G. (1988). Fractures in Thoroughbred race horses. Cornell Veterinary Journal 78: 77-133.

Lundvall, R.L. (1969). Ataxia of colts as a result of injuries. Norden News Summer, 6.

McCoy, D.J., Shires, P.K. and Beadle, R. (1984). Ventral approach for stabilization of atlantoaxial subluxation secondary to odontoid fracture in a foal. Journal of the American Veterinary Medical Association 185: 545-549.

Nixon, A.J. (1996). Fractures of the vertebrae. In: Equine Fracture Repair First edition. Philadelphia: Saunders

Nixon, A.J. and Stashak, T.S. (1988). Laminectomy for relief of atlantoaxial subluxation in four horses. Journal of the American Veterinary Medical Association 193: 677-682.

Owen, R.R. and Smith Maxie, L.L. (1978). Repair of fractured dens of the axis in a foal. Journal of the American Veterinary Medical Association 173: 854-856. Papageorges, M., Gavin, P.R., Sande, R.D., Barbee, D.D. and Grant, B.D. (1987). Radiographic and myelographic examination of the cervical vertebral column in 306 ataxic horses. Veterinary Radiology 28: 53-59.

Robinson, P.A. and Currall, J.H.S. (1981). Surgical repair of a cervical fracturedislocation in a mature horse. New Zealand Veterinary Journal 29: 28-32. Ryan, T.T.K.F. (1982). Fractures of the odontoid process of the axis. Journal of Bone and Joint Surgery 64: 417-421.

Sandier, A.N. and Tatot, C.H. (1976). Review of the effect of spinal cord trauma on the vessels and blood flow in the spinal cord. Journal of Neurosurgery 45: 638-645.

Schneider, J.E. (1981). Immobilizing cervical vertebral fractures. Proceedings American Association of Equine Practitioners 27: 253-255.

Slone, D.E., Bergfeld, W.A. and Walker, T.L. (1979). Surgical decompression for traumatic atlantoaxial subluxation in a weanling filly. Journal of the American Veterinary Medical Association 174: 1234-1236.

Trotter, E.J. (1972). Surgical repair of fractured axis in a dog. Journal of the American Veterinary Medical Association 161: 303-306.

Vaughan, L.C. and Mason, B.J.E. (1976). A clinical-pathological study of racing accidents in horses. Surgery department of Royal Veterinary College, Hawkshead Ln, North Mymms, Hatfield, Herts, England. RVC: London. Verheggen, R. and Jansen, J. (2004). Fractures of the odontoid process: Analysis of the functional results after surgery. European Spine Journal 3: 146-150. Wagner, P.C., Bagby, G.W., Grant, B.D., Gallina, A., Ratzlaff, M. and Sande, R. (1979). Surgical stabilization of the equine cervical spine. Journal of the American Veterinary Medical Association 8: 7-12. 